\title{
RNA interference-based resistance against a legume mastrevirus
}

\author{
Nazia Nahid, Imran Amin, Rob W Briddon and Shahid Mansoor
}

\begin{abstract}
Background: RNA interference (RNAi) is a homology-dependant gene silencing mechanism and has been widely used to engineer resistance in plants against RNA viruses. However, its usefulness in delivering resistance against plant DNA viruses belonging to family Geminiviridae is still being debated. Although the RNAi approach has been shown, using a transient assay, to be useful in countering monocotyledonous plant-infecting geminiviruses of the genus Mastrevirus, it has yet to be investigated as a means of delivering resistance to dicot-infecting mastreviruses. Chickpea chlorotic dwarf Pakistan virus (CpCDPKV) is a legume-infecting mastrevirus that affects chickpea and other leguminous crops in Pakistan.

Results: Here a hairpin (hp)RNAi construct containing sequences encompassing part of replication-associated protein gene, intergenic region and part of the movement protein gene of CpCDPKV under the control of the Cauliflower mosaic virus $35 \mathrm{~S}$ promoter has been produced and stably transformed into Nicotiana benthamiana. Plants harboring the hairpin construct were challenged with CpCDPKV. All non-transgenic N. benthamiana plants developed symptoms of CpCDPKV infection within two weeks post-inoculation. In contrast, none of the inoculated transgenic plants showed symptoms of infection and no viral DNA could be detected by Southern hybridization. A real-time quantitative PCR analysis identified very low-level accumulation of viral DNA in the inoculated transgenic plants.

Conclusions: The results presented show that the RNAi-based resistance strategy is useful in protecting plants from a dicot-infecting mastrevirus. The very low levels of virus detected in plant tissue of transgenic plants distal to the inoculation site suggest that virus movement and/or viral replication was impaired leading to plants that showed no discernible signs of virus infection.
\end{abstract}

\section{Introduction}

RNA interference (RNAi) is a homology-dependent mechanism that involves the specific degradation of cellular RNA by a complex of enzymes. The phenomenon was first discovered in plants and was called "post-transcriptional gene silencing" (PTGS) [1]. RNAi is involved in controlling developmental processes and also as a defense against viruses, transposons and foreign nucleic acids. The key role in RNAi is played by small RNAs [known as short interfering RNA (siRNA) and micro RNA (miRNA)], which act as effectors of silencing [2]. Plants recognize dsRNA as foreign/aberrant and this is cleaved into 21-26 nt siRNAs by a ribonuclease III-like enzyme called Dicer [3]. One strand of the siRNA is

\footnotetext{
* Correspondence: shahidmansoor7@gmail.com

Agricultural Biotechnology Division, National Institute for Biotechnology and Genetic Engineering (NIBGE), P O Box 577, Jhang Road, Faisalabad, Pakistan
}

incorporated into a ribonuclease complex known as the RNA-induced silencing complex (RISC) and serves as the guide for sequence-specific degradation of homologous mRNAs [4]. siRNAs homologous to promoter regions of target genes induce transcriptional gene silencing (TGS) which results in promoter methylation and consequent inhibition of transcription. siRNAs homologous to coding regions induce PTGS, which results in sequence-specific RNA degradation. PTGS and TGS are mechanistically related, as both involve the production of siRNA [5].

RNAi can be used to engineer resistance in plants against viruses. Plants expressing a copy of a viral gene in sense and/or antisense orientation can show resistance upon infection with the virus (or other virus containing identical sequences) through RNAi. One of the first studies investigating DNA-directed RNAi in plants 
compared the ability of constructs expressing transcripts of sense, antisense and both polarities to yield resistance to an RNA virus in tobacco and silence an endogenous GUS reporter gene in rice [6]. In both cases it was shown that duplex RNA (expression of both polarities simultaneously) was more effective than expression of either sense or antisense RNA alone. Further studies showed that RNAi can be more efficiently induced using transgenes that express self-complementary "hairpin" (hp)RNA [7]. The hpRNA transgene is simply composed of a plant promoter and terminator between which an inverted repeat sequence of the target gene (sense and anti-sense) is inserted with a spacer region or intron between the repeats. The RNA transcribed from such a transgene hybridizes with itself to form a hairpin structure comprising a single-stranded loop region, encoded by the spacer region/intron, and a base-paired stem encoded by the inverted repeats, which mimics the dsRNA structure that induces RNAi. The whole length of the stem acts as a substrate for the generation of siRNAs, whereas the spacer region/intron is not involved in siRNA production but is required for the stability of the construct and appears to enhance the efficacy of silencing when directed against viruses [8].

Geminiviruses are single-stranded (ss)DNA viruses that affect a wide range of economically important crops throughout the warmer regions of the world [9-11]. Viruses of the family Geminiviridae are divided between the four genera (Mastrevirus, Curtovirus, Topocuvirus and Begomovirus) based on host range, genome organization and insect vector [12]. Although they are ssDNA viruses that replicate in the nucleus and have no dsRNA phase within their replication cycle, geminiviruses are known to trigger PTGS in plants with the production of virus-specific siRNA $[13,14]$. In contrast to RNA viruses, which can only be affected by PTGS, geminiviruses may be targeted by both PTGS and TGS. TGS is implicated when siRNAs corresponding to the promoter regions are produced that lead to methylation of the promoter and thus inhibition of transcription [15]. TGS was shown to be effective against the begomovirus Mungbean yellow mosaic virus (MYMV) in a transient assay [16].

The genus Mastrevirus encompasses viruses with monopartite genomes that are transmitted by leafhoppers. Although the majority of mastreviruses infect monocotyledonous plants, a small number infect dicots [17-21]. A group of closely related mastreviruses, that includes Chickpea chlorotic dwarf Pakistan virus (CPCDPKV), cause chickpea stunt disease (CSD) and also infect a number of other legume and non-leguminous crops. CPCDPKV causes significant losses to chickpea cultivation in Pakistan.

The genome of CPCDPKV, in common with all mastreviruses, contains four open reading frames (ORFs;
Figure 1) [22]. Two ORFs (V1 and V2, encoding the coat protein $[\mathrm{CP}]$ and movement protein $[\mathrm{MP}]$, respectively) are encoded on the virion-sense strand and two ORFs ( $\mathrm{C} 1$ and $\mathrm{C} 2)$ are encoded on the complementarysense strand [19]. The replication associated protein (Rep; the only virus-encoded protein required for viral DNA replication) is translated from a spliced mRNA, which fuses the $\mathrm{C} 1$ and $\mathrm{C} 2 \mathrm{ORFs}$ following the deletion of an intron, whereas the C1 ORF encodes the RepA protein, which is translated from an unspliced mRNA. The ORFs on the virion- and complementary-sense strands are separated by a large intergenic region (LIR) and a small intergenic region (SIR). The LIR contains a predicted hairpin-loop structure with the conserved (between geminiviruses) nonanucleotide motif (TAATATTAC), which forms part of the origin of virionstrand DNA replication, in the loop. The aim of the study described here was to investigate RNAi as a means of engineering resistance against CPCDPKV.

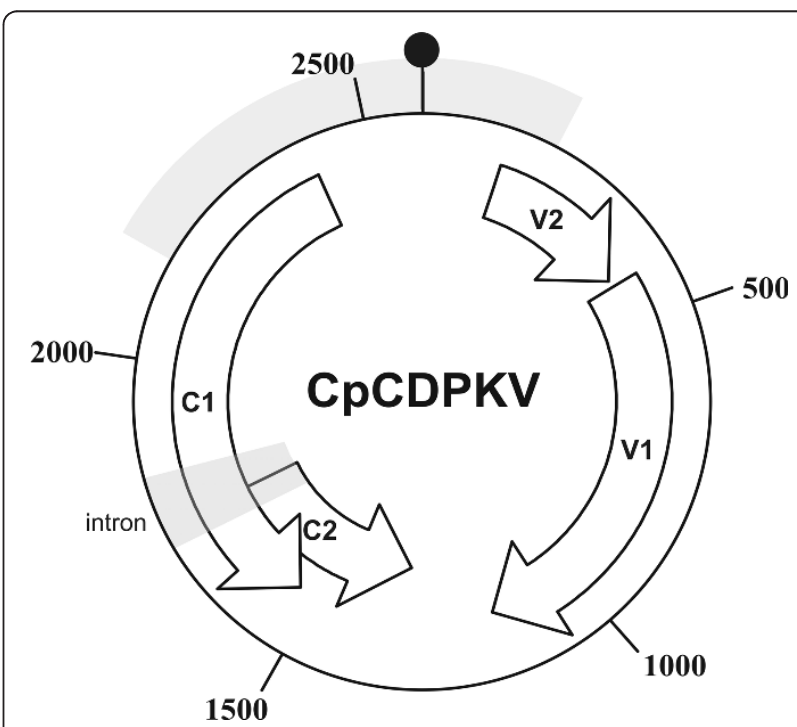

Figure 1 Sequences of the CPCDPKV genome used to produce the hairpin-RNAi construct. The diagram shows the circular DNA genome of CPCDPKV. Shown are the open-reading frames (ORFs) $\mathrm{V} 1$ and V2 (encoding the coat protein and movement protein, respectively), in the virion-sense and the $\mathrm{C}_{1}$ and $\mathrm{C} 2$ (encoding the replication associated protein [Rep; from a spliced product of the C1 and C2 ORFs] and the Rep A [from the C1 ORF], respectively), as well as the intron spliced from a mRNA from which Rep is translated. The large intergenic (non-coding) region (LIR) sits between the $\mathrm{C} 1$ and $\mathrm{V} 1 \mathrm{ORFs}$, whereas the small intergenic region (SIR) sits between the C2 and V2 ORFs. The LIR contains a predicted hairpin-loop structure which contains (within the sequence of the loop) the conserved (between geminiviruses) TAATATTAC sequence which forms part of the origin of virion-strand DNA replication. The position of the hairpin-loop structure is indicated by the black circle at position zero. The CPCDPK virus sequences (730 bp) used to produce the hairpin RNAi construct is shown by the grey arc; this spans the 5' Rep, LIR and 5' MP sequences. 


\section{Results}

Transgenic N. benthamiana plants are resistant to CpCDPKV infection

A hpRNAi construct, containing sequences spanning the $\mathrm{N}$-terminus of the Rep gene, the LIR and the N-terminus of the MP gene of CPCDPKV (Figure 1), was produced. Nicotiana benthamiana was transformed with the hpRNA construct (Chp6pFGC5941) by conventional Agrobacterium-mediated transformation and a single line, shown to harbor the construct by PCR amplification with the primers used to amplify the CPCDPKV fragments during construction, was selected for analysis. Both transgenic (25 plants) and non-transgenic (10 plants) N. benthamiana at the four true leaf stage were infiltrated with an Agrobacterium culture harboring a construct for the infectivity of CpCDPKV. All 10 non-transgenic plants showed symptoms of virus infection in the upper, newly emerging leaves at 14 days post-inoculation (dpi) consisting of foliar yellowing and curling (Figure $2 \mathrm{~B}$ ). Plants ceased to grow and died at approximately $25 \mathrm{dpi}$. In contrast, all transgenic plants remained symptomless (Figure 2C), continued to grow and flowered, producing via seed (results not shown). These results are consistent with the hpRNA construct providing resistance to virus infection.

Southern blot analysis of DNA samples extracted from the upper (non-inoculated) leaves of inoculated plants, probed for the presence of CPCDPKV DNA, showed the presence of high levels of typical ss and dsDNA viral forms in symptomatic, non-transgenic N. benthamiana plants (Figure 3). No hybridizing bands were detected in inoculated transgenic plants. These results suggest that transgenic expression of the hpRNAi construct was able to prevent symptomatic infection of plants by CPCDPKV.

\section{Determination of virus titer in inoculated plants by quantitative PCR}

The titre of CPCDPKV in inoculated transgenic and infected non-transgenic plants was determined by quantitative real-time PCR, the results of which are summarized in Figure 4 and Table 1. A standard curve was established using dilutions of the CPCDPKV clone and this was used to calculate viral DNA concentrations in plants by comparison of the threshold cycles $(\mathrm{Ct})$ to the standard curve. The overall efficiency of these reactions was $98 \%$.

PCR reactions with DNA extracted from healthy, noninoculated $N$. benthamiana plants and from a reaction with no input (template) DNA had Ct values equivalent to the total number of cycles used in the experiment, indicating that the threshold level was not achieved and thus that these reactions contained no detectable viral DNA. In contrast, four CPCDPKV-infected control (non-transgenic) $N$. benthamiana plants were shown to contain relatively large amounts of viral DNA (between 0.46 and $2.3 \mathrm{ng}$ per $10 \mu \mathrm{g}$ of genomic DNA). This relatively large variation ( $\sim 5$ fold) in viral DNA levels between different infected plants likely results from the plants being at different infection stages at the time of sampling (meaning that differing numbers of cells were infected).

Although Southern blot analysis was unable to detect viral DNA in the inoculated transgenic plants, the quantitative PCR analysis showed the presence of viral DNA at between 0.0813 and $0.172 \mathrm{pg}$ per $10 \mu \mathrm{g}$ of genomic DNA. This is only an $\sim 2$ fold variation, meaning that the transgenic plants showed less variability in viral DNA levels, even though more plants were examined. However, the difference in viral DNA levels between transgenic and non-transgenic plants was striking - between 2,600 and 28,000 fold.

To assess the specificity of the PCR, a melt curve analysis of the resulting PCR products was conducted (Additional file 1). The analysis showed only a single peak, indicative of the melting of the PCR product at a single temperature, showing that only a single product was amplified.

\section{Discussion}

The RNAi approach has been investigated extensive as a means of delivering resistance to begomoviruses in

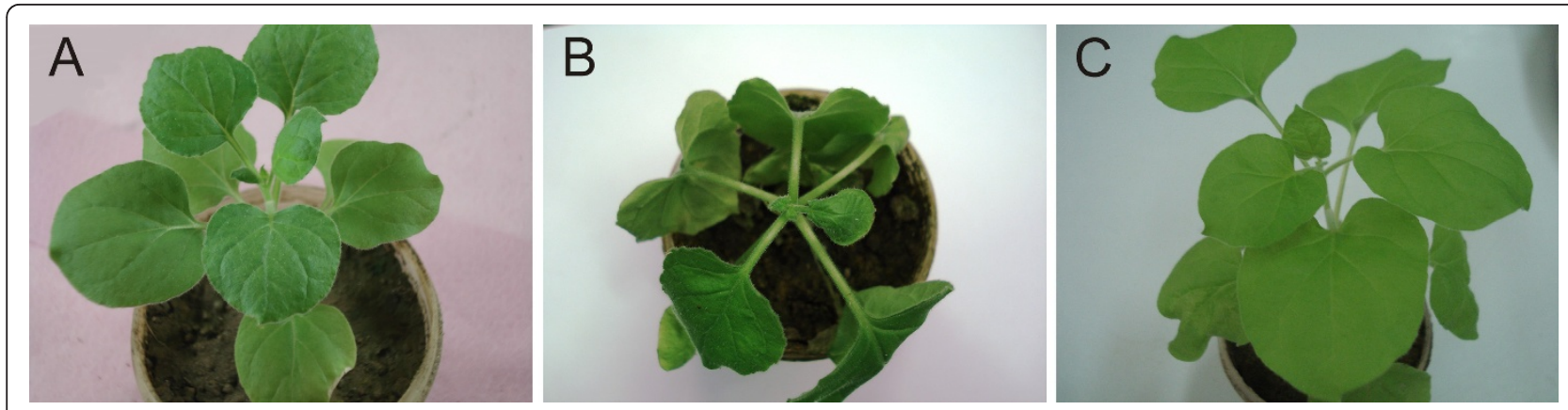

Figure 2 RNAi-mediated resistance to CpCDPKV in transgenic $\mathbf{N}$. benthamiana. Shown are a healthy non-inoculated $\mathrm{N}$. benthamiana plant (A) and CpCDPKV-inoculated transgenic (B) and non-transgenic (C) N. benthamiana plants. Photographs were taken at 17 days post-inoculation. 


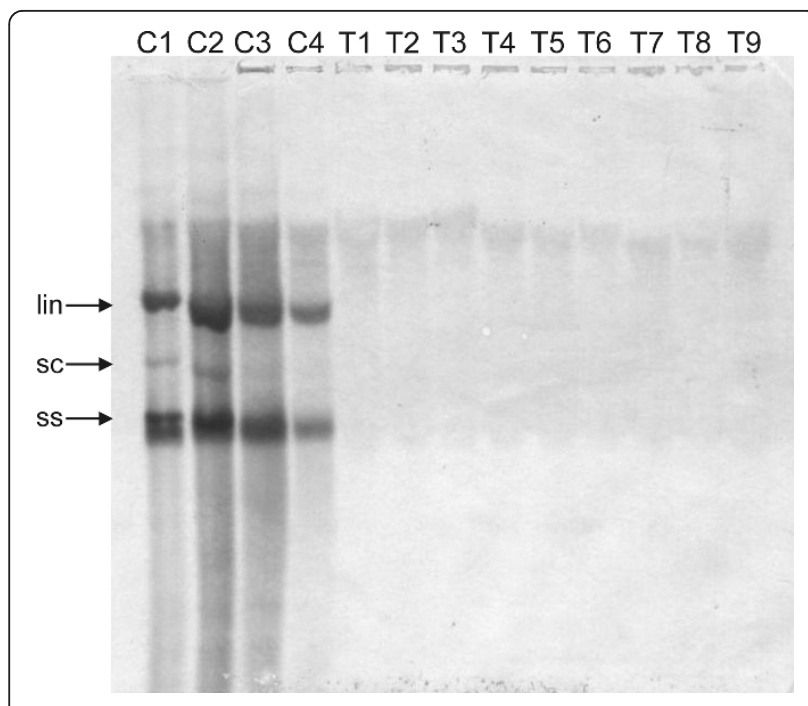

Figure 3 Southern blot detection of CPCDPKV DNA in $N$. benthamiana plants. The samples run on the gel were total DNA extracts (500 ng) from symptomatic, CpCDPKV infected nontransgenic N. benthamiana plants (lanes C1-C4) and transgenic N. benthamiana plants, harboring the hairpin RNAi construct, inoculated with CpCDPKV (lanes T1-T9). Viral DNA forms are indicated as supercoiled (sc), single-stranded (ss) and linear (lin). plants $[23,24]$. In at least one case this has led to the first successful field tests of RNAi-based resistant plant lines $[25,26]$. However, the lack of success of other studies has led to some ask whether this approach can, ultimately, succeed; with virus diversity and virusencoded suppressors of RNAi as possible negative indicators of the ultimate success of the RNAi-based approach $[27,28]$. For mastreviruses, specifically the monocot-infecting Maize streak virus, a proteinmediated resistance approach has proven successful [29] and recently, using a transient cell culture assay, the potential usefulness of the RNAi approach to MSV resistance was shown [30]. Here we have shown that stable integration of a hpRNAi construct provides $N$. benthamiana with resistance to a dicot-infecting mastrevirus.

Although all transgenic plants remained symptomless and Southern blot analysis did not show the presence of viral DNA, quantitative PCR analysis was able to show the presence of very low viral DNA titers; a 2,600 to 28,000 fold difference between transgenic and nontransgenic plants. These results are consistent since PCR is a far more sensitive technique than Southern

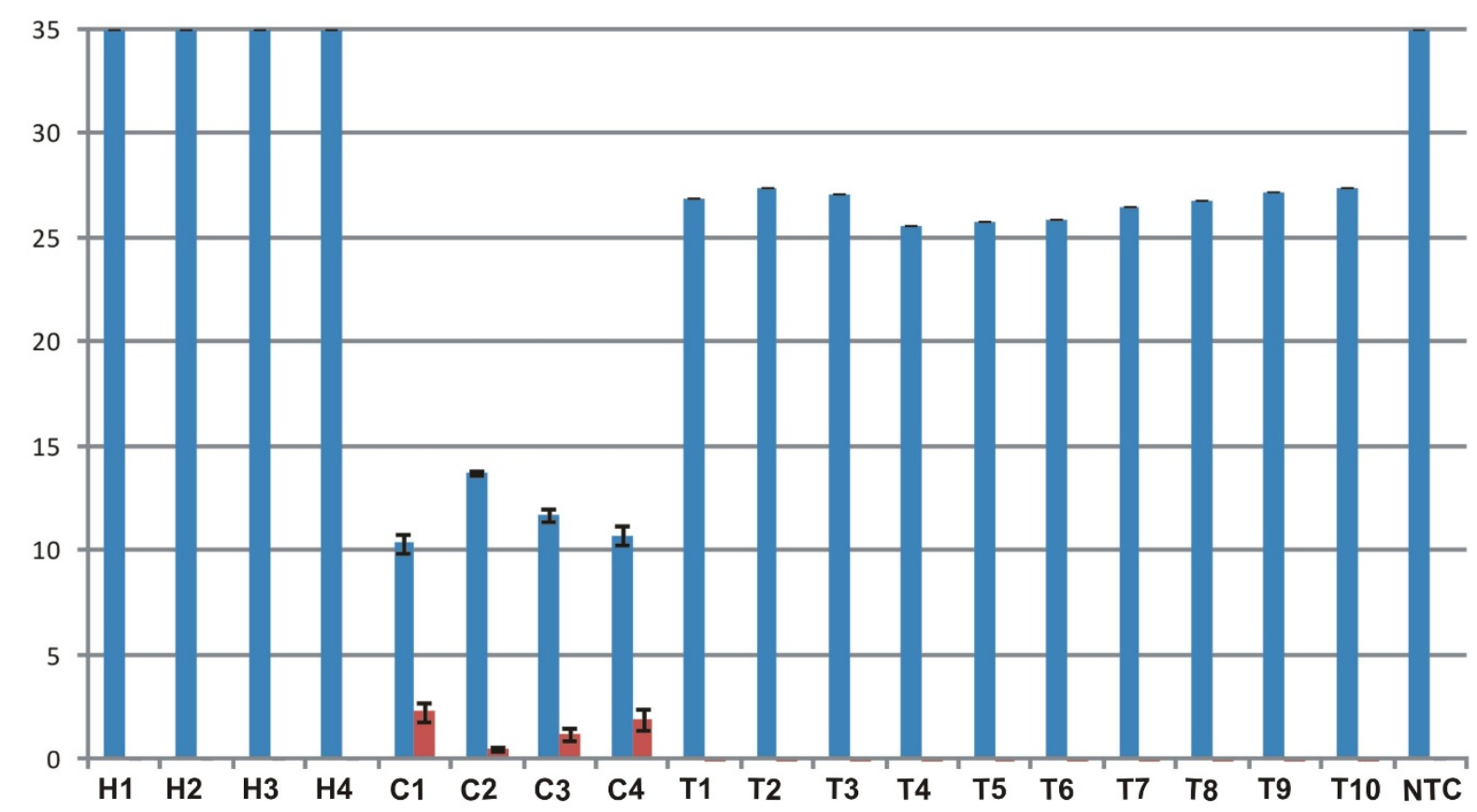

- Mean Ct

- Mean Conc. (ng/10ng genomic DNA)

Figure 4 Quantitative real-time polymerase chain reaction analysis of viral DNA levels in transgenic and non-transgenic, CpCDPKV -inoculated $N$. benthamiana plants. Shown is a bar graph of threshold cycle (Ct) values (blue bars) and derived viral DNA concentrations (ng/ $10 \mathrm{ng}$ genomic DNA; brown bars) for reactions with DNA extracted from healthy non-inoculated (H1-H4), infected non-transgenic (C1-C4) and inoculated transgenic (T1-T10) N. benthamiana plants. The results of a PCR reaction with no input (template) DNA is shown for comparison (NTC). Each bar is the mean of three repeated PCR reactions and the error bars indicate standard deviation. 
Table 1 Quantitative real-time PCR estimation of viral DNA levels for CpCDPKV-inoculated transgenic and non-transgenic plants

\begin{tabular}{|c|c|c|c|c|}
\hline Sample* & Mean $\mathrm{Ct}^{@}$ & Mean viral DNA concentration ${ }^{@}(\mathrm{ng} / 10 \mathrm{ng}$ genomic DNA) & Standard deviation of CT & Standard deviation viral DNA concentration \\
\hline Standard 1 & 6.92 & 10 & 2.087 & 0.0000 \\
\hline Standard 2 & 12.61 & 1 & 0.107 & 0.0000 \\
\hline Standard 3 & 17.33 & 0.1 & 0.257 & 0.0000 \\
\hline Standard 4 & 21.1 & 0.01 & 0.877 & 0.0000 \\
\hline Standard 5 & 26.07 & 0.001 & 1.207 & 0.0000 \\
\hline Healthy 1 & 35 & 0.0000 & 0.0000 & 0.0000 \\
\hline Healthy 2 & 35 & 0.0000 & 0.0000 & 0.0000 \\
\hline Healthy 3 & 35 & 0.0000 & 0.0000 & 0.0000 \\
\hline Healthy 4 & 35 & 0.0000 & 0.0000 & 0.0000 \\
\hline Control 1 & 10.36 & 2.3 & 0.678 & 0.4632 \\
\hline Control 2 & 13.78 & 0.46 & 0.899 & 0.0927 \\
\hline Control 3 & 11.7 & 1.22 & 1.008 & 0.295 \\
\hline Control 4 & 10.74 & 1.92 & 0.256 & 0.467 \\
\hline Transgenic 1 & 26.85 & 0.0000938 & 0.7862 & 0.0000303 \\
\hline Transgenic 2 & 27.36 & 0.0000825 & 0.5655 & 0.00003065 \\
\hline Transgenic 3 & 27.07 & 0.0000842 & 0.5603 & 0.00005189 \\
\hline Transgenic 4 & 25.56 & 0.000172 & 1.453 & 0.00007732 \\
\hline Transgenic 5 & 25.73 & 0.000159 & 0.8234 & 0.00002111 \\
\hline Transgenic 6 & 25.83 & 0.000152 & 0.3278 & 0.00003265 \\
\hline Transgenic 7 & 26.5 & 0.000111 & 0.9562 & 0.00002111 \\
\hline Transgenic 8 & 26.77 & 0.0000972 & 0.4445 & 0.00002241 \\
\hline Transgenic 9 & 27.16 & 0.0000814 & 0.8129 & 0.00002231 \\
\hline Transgenic 10 & 27.35 & 0.0000813 & 1.421 & 0.00001317 \\
\hline NTC & 35 & 0.0000 & 0.0000 & 0.0000 \\
\hline
\end{tabular}

*The samples are indicated as non-inoculated healthy N. benthamiana plants (Healthy 1-4), infected non-transgenic plants (Control 1-4) and inoculated transgenic plants (Transgenic 1-10). The results of PCR reactions with known amounts of viral input (template) DNA, used to produce the standard curve, are indicated (Standard 1-5). A reaction with no input (template) DNA (NTC) was included as a control.

@ For each sample PCR reactions were conducted in triplicate and the mean value and standard deviations between the values, for both the threshold cycle (Ct) and mean concentrations (in ng viral DNA per $10 \mathrm{ng}$ of plant genomic DNA) are given. 
blotting, indicating that virus DNA levels in transgenic plants are below the detection threshold of Southern blotting. This finding is very similar to the results obtained for infections of the DNA A components of many bipartite begomoviruses in the absence of the DNA B. For bipartite begomoviruses both the DNA A and DNA B components are required for symptomatic infections of plants [31,32]. Nevertheless, for most bipartite begomoviruses examined, the DNA A component can spread systemically in plants in the absence of the DNA B [33-35]. Plants infected with only DNA A exhibit no symptoms and reduced viral DNA levels. These results suggested that, following Agrobacteriummediated inoculation, the DNA A is able to gain access to the phloem and spread throughout the plant (either as virions or a nucleoprotein complex involving the $\mathrm{CP}$ ), but is unable to reestablish infection in the upper (younger, actively growing) parts of the plant in the absence of the genes products encoded by DNA B (which are involved in virus intra- and intercellular movement [36]. The RNAi construct used here, by virtue of containing sequences of both the MP gene and its promoter, should induce both PTGS and TGS of the viral MP gene. It is thus possible, in a manner analogous to the situation with DNA A only infections, that RNAi-mediated down-regulation of MP expression prevented efficient spread of the virus from the site of inoculation to young, actively growing tissues of the plant.

An alternative, and possibly more plausible, explanation of the phenomenon seen in the hpRNAi construct containing plants is that virus replication (and possibly also movement) is severely impaired. However, possibly minute amounts of virus can move into the phloem and spread throughout the plant, but at levels that are insufficient to reestablish infection of cells in the upper (younger, actively growing) parts of the plant - cells which also harbor the hpRNAi construct. The lack of variability in DNA levels in the younger tissues of inoculated transgenic plants $(\sim 2$ fold in comparison to $\sim 5$ fold in non-transgenic infected plants) might suggest that viral DNA replication is not occurring, or occurring at very low levels, in these tissues.

Further studies will address the precise mechanism of the resistance by, for example looking for small RNAs derived from the transgene and whether TGS, in addition to PTGS, is involved. Additionally the ability of the hpRNAi construct, derived from CPCDPKV, will be assessed for its ability to provide protection to other related viruses; such as Chickpea chlorotic dwarf Sudan virus and the recently identified Chickpea chlorotic $d$ warf Syria virus [21]. Ultimately the aim is to produce chickpea lines harboring an hpRNAi construct which can provide a broad spectrum resistance to these legume-infecting mastreviruses.

\section{Methods}

Production of a hairpin RNAi construct against CpCDPKV For CpCDPKV one hpRNA construct, Chp6pFGC5941, was designed. This construct was based on a part of Rep (that is also a part of RepA) gene, part of the movement protein (MP) gene and the LIR (Figure 1). Specific sets of primers (Table 2) were designed with suitable restriction sites for the PCR amplification of a DNA fragment of about $730 \mathrm{bp}$ in sense and antisense orientations. A clone of CpCDPKV (acc. no. AM849097 [19]) was used as template in PCR. These PCR products were separately cloned into the T/A cloning vector pTZ57R/ $\mathrm{T}$ to yield pChP6S and pChP6AS. For cloning the gene fragment in the RNAi vector pFGC5941 in sense orientation, the fragment was excised from pChP6S by using $X h o I$ and NcoI and ligated in suitably restricted pFGC5941 to produce pChP6SRNAi. Then a full fragment was excised from the pChP6AS in antisense orientation by using $X b a \mathrm{I}$ and cloned in PChP6SRNAi to yield the final hpRNAi construct ChP6pFGC5941. The integrity of the construct was confirmed by restriction digestion and sequencing (results not shown).

\section{Plant transformation}

$N$. benthamiana was transformed with the RNAi construct (ChP6pFGC5941) by the leaf disc method using Agrobacterium tumefaciens strain LBA4404 [37,38]. Integration of the construct in the transgenic line was confirmed by PCR using the primer sets used to produce the construct (Table 2). The transgene showed no adverse effect on the growth of plants with all transgenic plants showing a normal phenotype and producing viable seed (results not shown).

Table 2 Oligonucleotide primers used in the production of the RNAi construct

\begin{tabular}{|c|c|c|c|}
\hline Primer & Orientation & Primer sequences ${ }^{\#}$ & Cloning sites* \\
\hline Chp6SF & sense/forward & 5'CCAACTCGAGTTATCAAGCTGGACAAGAGC 3' & Xhol \\
\hline Chp6SR & sense/reverse & 5'CCTCCCATGGTTCGCCTIAAACAGAAGG 3' & Ncol \\
\hline Chp6ASF & antisense/forward & 5'CCTCTCTAGATTCGCCTTAAACAGAAGG 3' & Xbal \\
\hline Chp6ASR & antisense/reverse & 5'CCAATCTAGATTATCAAGCTGGACAAGAGC 3' & Xbal \\
\hline
\end{tabular}

* Restriction endonuclease recognition sequences introduced into the primers to facilitate cloning of fragments into pFGC5941.

\# The introduced restriction endonuclease recognition sequences are underlined. 


\section{Inoculation of plants with CpCDPKV}

Twenty-five $\mathrm{T}_{1}$ transgenic $N$. benthamiana plants harboring the RNAi construct, obtained from the self-pollination of $\mathrm{T}_{\mathrm{o}}$ plants, were agro-infiltrated with a construct for the infectivity of CpCDPKV as described previously [19]. Ten non-transgenic plants of the same age (4 weeks old) were infiltrated as controls. All agro-infiltrated plants were observed periodically for the appearance of symptoms. The presence of virus in transgenic and non-transgenic plants was detected by Southern hybridization and realtime PCR.

\section{Southern hybridization for the detection of viral DNA}

Total DNA was isolated from the inoculated plants [39] and $500 \mathrm{ng}$ of DNA was resolved on 1\% agarose gel in $0.5 \times$ TAE buffer. Blotting was performed as described earlier [40]. The blot was hybridized with a 1000 bp biotinlabeled DNA probe (prepared using a Biotin DecaLabel ${ }^{\text {TM} D N A ~ l a b e l i n g ~ k i t ~[F e r m e n t a s]) ~ c o n t a i n i n g ~ p o r t i o n s ~ o f ~}$ genes encoding movement protein (MP) and coat protein (CP). The hybridization and DNA detection was performed according to the manufacturer's recommendations.

\section{Real-time PCR quantification of viral DNA in plants}

Quantitative PCR (qPCR) was performed for the quantification of viral DNA in transgenic plants (showing resistance against $\mathrm{CPCDPKV)}$ and non-transgenic plants (showing infection for CPCDPKV) by using SYBER green dye (IQ SYBER Green supermix, BIO-RAD USA) as described previously [41]. Based on the nucleotide sequence of CpCDPKV (AM849097), a primer pair QF (5'TAAAAGGCGCACTAATGGGTAGACCGTAGA3' spanning nucleotide coordinates 102-131) and QR (5'GGCGATAACCACCTTCCCG3' - spanning nucleotide coordinates 251-233) was designed to amplify a product of $150 \mathrm{bp}$ specific to CpCDPKV. Young leaf samples were collected from the inoculated plants at 17 dpi and qPCR was performed in three replications along with the standards and controls.

\section{Additional material}

Additional file 1: Melt curve analysis of the products produced during the qPCR analysis. The graph shows a plot of the negative derivative of fluorescence versus temperature $\left({ }^{\circ} \mathrm{C}\right)$ for each amplification tube. A single peak is evident, indicative of the amplification of a single product.

\section{Acknowledgements}

NN was supported by a fellowship from Higher Education Commission (HEC), Government of Pakistan. RWB is employed by HEC under "Foreign Faculty Hiring" program. This work was supported in part by a research grant from International Center for Biotechnology and Genetic Engineering (ICGEB), Trieste, Italy.

\section{Authors' contributions}

NN, IA performed the experiments. RWB and SM conceived the study. NN, IA, RWB and SM wrote the manuscript. All authors read and approved the final manuscript.

\section{Competing interests}

The authors declare that they have no competing interests.

Received: 15 March 2011 Accepted: 2 November 2011

Published: 2 November 2011

\section{References}

1. Baulcombe DC: Unwinding RNA Silencing. Science 2000, 290:1108.

2. Brodersen $P$, Voinnet $O$ : The diversity of RNA silencing pathways in plants. Trends Genet 2006, 22:268-280.

3. Bernstein E, Caudy AA, Hammond SM, Hannon GJ: Role for a bidentate ribonuclease in the initiation step of RNA interference. Nature 2001, 409:363-366

4. Hammond SM, Bernstein E, Beach D, Hannon GJ: An RNA-directed nuclease mediates post-transcriptional gene silencing in Drosophila cells. Nature 2000, 404:293-296.

5. Vaucheret $H$, Fagard M: Transcriptional gene silencing in plants: targets, inducers and regulators. Trends Genet 2001, 17:29-35.

6. Waterhouse $P$, Graham MW, Wang M-B: Virus resistance and gene silencing in plants can be induced by simultaneous expression of sense and antisense RNA. Proc Natl Acad Sci USA 1998, 95:13959-13964.

7. Smith NA, SP S, Wang M-B, Stoutjesdijk PA, Green AG, Waterhouse PM: Total silencing by intron-spliced hairpin RNAs. Nature 2000, 407:319-320.

8. Wesley SV, Helliwell C, Smith NA, Wang M-B, Rouse D, Liu Q, Gooding PS, Singh SP, Abbott D, Stoutjesdijk PA, et al: Constructs for efficient, effective and high throughput gene silencing in plants. Plant J 2001, 27:581-590.

9. Moffat AS: Geminiviruses emerge as serious crop threat. Science 1999, 286:1835.

10. Boulton Ml: Geminiviruses: major threats to world agriculture. Ann Appl Biol 2003, 142:143.

11. Mansoor S, Briddon RW, Zafar Y, Stanley J: Geminivirus disease complexes: an emerging threat. Trends Plant Sci 2003, 8:128-134.

12. Stanley J, Bisaro DM, Briddon RW, Brown JK, Fauquet CM, Harrison BD, Rybicki EP, Stenger DC: Geminiviridae. In Virus Taxonomy, VIIIth Report of the ICTV. Edited by: Fauquet CM, Mayo MA, Maniloff J, Desselberger U, Ball LA. London: Elsevier/Academic Press; 2005:301-326.

13. Lucioli A, Noris E, Brunetti A, Tavazza R, Ruzza V, Castillo AG, Bejarano ER, Accotto GP, Tavazza M: Tomato yellow leaf curl Sardinia virus Rep-derived resistance to homologous and heterologous geminiviruses occurs by different mechanisms and is overcome if virus-mediated transgene silencing is activated. J Virol 2003, 77:6785-6798.

14. Chellappan P, Vanitharani R, Fauquet CM: Short interfering RNA accumulation correlates with host recovery in DNA virus-infected hosts, and gene silencing targets specific viral sequences. J Virol 2004, 78:7465-7477.

15. Mette MF, Aufsatz W, van der Winden J, Matzke MA, Matzke AJM: Transcriptional silencing and promoter methylation triggered by doublestranded RNA. EMBO J 2000, 19:5194-5201.

16. Pooggin M, Shivaprasad PV, Veluthambi $K$, Hohn T: RNAi targeting of DNA virus in plants. Nat Biotechnol 2003, 21:131-132.

17. Morris BAM, Richardson KA, Haley A, Zhan X, Thomas JE: The nucleotide sequence of the infectious cloned DNA component of tobacco yellow dwarf virus reveals features of geminiviruses infecting monocotyledonous plants. Virology 1992, 187:633-642.

18. Liu L, van Tonder T, Pietersen G, Davies JW, Stanley J: Molecular characterization of a subgroup I geminivirus from a legume in South Africa. J Gen Virol 1997, 78:2113-2117.

19. Nahid N, Amin I, Mansoor S, Rybicki EP, van der Walt E, Briddon RW: Two dicot-infecting mastreviruses (family Geminiviridae) occur in Pakistan. Arch Virol 2008, 153:1441-1451.

20. Thomas J, Parry J, Schwinghamer M, Dann E: Two novel mastreviruses from chickpea (Cicer arietinum) in Australia. Arch Virol 2010, 155:1777-1788. 
21. Mumtaz H, Kumari SG, Mansoor S, Martin DP, Briddon RW: Analysis of the sequence of a dicot-infecting mastrevirus (family Geminiviridae) originating from Syria. Virus Genes 2011, 42:422-428.

22. Boulton MI: Functions and interactions of mastrevirus gene products. Physiological and Molecular Plant Pathology 2002, 60:243-255.

23. Vanderschuren H, Stupak M, Fütterer J, Gruissem W, Zhang P: Engineering resistance to geminiviruses - review and perspectives. Plant Biotechnol J 2007, 5:207-220.

24. Shepherd DN, Martin DP, Thomson JA: Transgenic strategies for developing crops resistant to geminiviruses. Plant Sci 2009, 176:1-11.

25. Aragão F, Faria J: First transgenic geminivirus-resistant plant in the field: The development of a RNAi-based agriculture technology. In Vitro Cell Dev Biol Anim 2010, 46:S5.

26. Aragão FJL, Faria JC: First transgenic geminivirus-resistant plant in the field. Nat Biotech 2009, 27:1086-1088.

27. Lucioli A, Sallustio DE, Barboni D, Berardi A, Papacchioli V, Tavazza R, Tavazza M: A cautionary note on pathogen-derived sequences. Nat Biotechnol 2008, 26:617-619.

28. Noris E, Lucioli A, Tavazza R, Caciagli P, Accotto GP, Tavazza M: Tomato yellow leaf curl Sardinia virus can overcome transgene-mediated RNA silencing of two essential viral genes. J Gen Virol 2004, 85:1745-1749.

29. Shepherd DN, Mangwende T, Martin DP, Bezuidenhout M, Kloppers FJ, Carolissen CH, Monjane AL, Rybicki EP, Thomson JA: Maize streak virusresistant transgenic maize: a first for Africa. Plant Biotechnol J 2007, 5:759-767.

30. Owor BE, Martin DP, Rybicki EP, Thomson JA, Bezuidenhout M, Lakay F, Shepherd DN: A rep-based hairpin inhibits replication of diverse Maize streak virus isolates in a transient assay. J Gen Virol 2011.

31. Stanley J: Infectivity of the cloned geminivirus genome requires sequences from both DNAs. Nature 1983, 305:643-645.

32. Hamilton WDO, Bisaro DM, Coutts RHA, Buck KW: Demonstration of the bipartite nature of the genome of a single-stranded DNA plant virus by infection with the cloned DNA components. Nucleic Acids Res 1983, 11:7387-7396

33. Klinkenberg FA, Stanley J: Encapsidation and spread of African cassava mosaic virus DNA $A$ in the absence of DNA $B$ when agroinoculated to Nicotiana benthamiana. J Gen Virol 1990, 71:1409-1412.

34. Evans $D$, Jeske H: DNA B facilitates, but is not essential for, the spread of Abutilon mosaic virus in agroinoculated Nicotiana benthamiana. Virology 1993, 194:752-757.

35. Briddon RW, Markham PG: Complementation of bipartite begomovirus movement functions by topocuviruses and curtoviruses. Arch Virol 2001 146:1811-1819.

36. Sanderfoot AA, Lazarowitz SG: Getting it together in plant virus movement: cooperative interactions between bipartite geminivirus movement proteins. Trends Cell Biol 1996, 6:353-358.

37. Horsch RB, Klee HJ: Rapid assay of foreign gene expression in leaf discs transformed by Agrobacterium tumefaciens: Role of T-DNA borders in the transfer process. Proc Natl Acad Sci USA 1986, 83:4428-4432.

38. Horsch RB, Fry JE, Hoffmann NL, Eichholtz D, Rogers SG, Fraley RT: A simple and general method for transferring genes into plants. Science 1985, 227:1229-1231.

39. Doyle JJ, Doyle JL: A rapid DNA isolation procedure for small quantities of fresh leaf tissue. Phytochemical Bulletin 1987, 19:11-15.

40. Sambrook J, Frisch EF, Maniatis T: Molecular Cloning: A Laboratory Manual New York: Cold Spring Harbor Laboratory Press; 1989.

41. Azhar MT, Amin I, Anjum Zl, Arshad M, Briddon RW, Mansoor S: Both malvaceous and non-malvaceous betasatellites are associated with two wild cotton species grown under field conditions in Pakistan. Virus Genes 2010, 41:417-424.

doi:10.1186/1743-422X-8-499

Cite this article as: Nahid et al.: RNA interference-based resistance against a legume mastrevirus. Virology Journal 2011 8:499.

\section{Submit your next manuscript to BioMed Central and take full advantage of:}

- Convenient online submission

- Thorough peer review

- No space constraints or color figure charges

- Immediate publication on acceptance

- Inclusion in PubMed, CAS, Scopus and Google Scholar

- Research which is freely available for redistribution

Submit your manuscript at www.biomedcentral.com/submit
Biomed Central 